\title{
Performance Analysis and Optimization of Cost 231-Hata Model for Mobile Communication in Nigeria
}

\author{
Akinyinka Olukunle Akande \\ Department of Electrical and \\ Electronic Engineering, Federal \\ University of Technology, Owerri, \\ Nigeria.
}

\author{
Folasade Abiola Semire \\ Department of Electronic and \\ Electrical Engineering, Ladoke \\ Akintola University of \\ Technology, Ogbomoso, Nigeria.
}

\author{
Zachaeus Kayode \\ Adeyemo \\ Department of Electronic and \\ Electrical Engineering, Ladoke \\ Akintola University of \\ Technology, Ogbomoso, Nigeria.
}

\begin{abstract}
Wireless communication encountered lots of issues in the channel as the signal is being propagated from transmitter to the receiver. The mobile users continue increasing and the quality of service is very poor due to unreliable nature of the channel. There has been signaling fading, attenuation, calls drop, interference, network capacity and signal loss which may be traced to path propagation problems. The data was collected from MTN base station at four different locations in Owerri namely - Egbu road, Mbaise road, Chukwuoma road and Awaka road. The drive test equipment with SonyEricsson W995 hand phone was used to measure Received Signal Strength (RSS). The MATLAB R2014a software was used for the simulation of parameters of the existing model and optimized model. The Measured Received Signal Power (MRSP) compared with the corresponding results obtained from Okumura-Hata, COST 231-Hata and Egli models. The Root Mean Square Error (RMSE) and Mean Absolute Percentage Error (MAPE) is used to evaluate the deviation in terms of the amount of error in each model. The result showed that COST 213-Hata model has RMSE $=9.75 \mathrm{~dB}$ and $M A P E=0.432 \%$. COST 231-Hata model was optimized using Least Square method (LSM) and optimized model showed better results with tuned COST 231-Hata model where $R M S E=4.33$ and $M A P E=0.221 \%$. The optimized model is recommended for better deployment and would be more accurate to be applied for path loss prediction in the suburban area.
\end{abstract}

\section{Keywords}

Received Signal Power, Least Square Method, COST 231Hata, RMSE

\section{INTRODUCTION}

The baseband signal is transmitted from base station antenna to mobile station antenna without physical connection or wires. The transmitted signal usually encounter attenuation problem in the channel between the transmitter and the receiver [1]. This signal strength reduced drastically with distance as a result of terrain factors. Some of these factors may be the mountain, height of the building, tall trees, and location of the antenna [2]. The attenuation suffered by a signal as it propagates from transmitter to the receiver is called path loss [3]. Path loss is due to many effects such as reflection, refraction, diffraction, and scattering of the signal [4]. This is an important effect that contributes to signal impairment by reducing its transmitted signal power in the mobile channel [5]. The design of mobile communication system depends on the path loss prediction and their suitability to signal propagation region [6]. Signal strength prediction and measurement are very important in the estimating performance of the mobile radio. Therefore, accurate estimation of radio path loss is essential for predicting coverage area of the base station and network capacity [7]. Propagation path loss models are the mathematical algorithm used for prediction, network planning, and design process [1]. In order to conduct meaningful terrain survey, network planning, and deployment of the network, path loss propagation models are employed [8]. The empirical models are based on observation and measurement in the proposed location [9]. Some of the existing models include Okumura-Hata, Stanford Interim University (SUI), COST 231-Hata, Lee, and Ericsson model [10]. Most of the base stations in Nigeria were planned with the existing model without considering the morphology and terrain of the city under deployment. Therefore, the models are suitable for signal power propagation in the study area. This research aimed at optimization of COST 231-Hata model for the suburban area using the measured Received Signal Strength (RSS) obtained from MTN network. It transmits at a frequency of $2100 \mathrm{MHz}$ in the study locations at Owerri, Nigeria.

\section{MEASUREMENT CAMPAIGN AND DATA COLLECTION}

The measurement equipment consists of a laptop with Test mobile Systems (TEMS) software installed. In addition, the system was interfaced with drive test phone, Sony- Ericsson W995 had $1.5 \mathrm{~m}$ antennae mounted on a moving vehicle. The Global Positioning System (GPS) receiver and a piece of the compass were connected to the computer. The GPS provides the location tracking for the system during data collection on a global map. This help to show roads, base station antenna and location name through global positioning satellite. The equipment was arranged inside a vehicle and short call was initiated at a speed of $30 \mathrm{~km} / \mathrm{h}$, the height of base station is 35 $\mathrm{m}$, mobile station antenna height is $1.5 \mathrm{~m}$, at $2100 \mathrm{MHz}$ frequency band, the Received Signal Code Power (RSCP) data were collected at various distances in Owerri. The voice call was recorded on a log file by TEMS in the computer with details information on call loss, connected call, call blocked, detected neighbor antenna, handover, and distance covered. The ACTIX software was used to extract the log file in the appropriate format into excel sheet for analysis.

\section{PROPAGATION MODELS}

There are many empirical models available for the prediction of mobile radio channel over irregular terrain. However, three models will be evaluated namely, Egli, Okumura-Hata, and COST 231-Hata models.

\subsection{Egli Model}

The model was developed to predict the path loss in over an irregular terrain [11]. Egli model is suitable for cellular 
communication scenarios where one antenna is fixeda $=115.81$, and other is mobile [12-13]. The model is used for frequency, distance and another parameter which is suitable for this study [14]. Egli model is not applicable in the area where some vegetative obstruction, such as trees or shrubbery is in the middle of the link[15]. The Egli model is given by [12-14] as

$$
\mathrm{L}_{\mathrm{p}(\text { Egli })}(\mathrm{dB})=\mathrm{P}_{\text {sys }}-20 \log \mathrm{h}_{(\mathrm{BST})}+76.3-10 \log \mathrm{h}_{(\mathrm{MS})},
$$
for $h_{(M S)} \leq 10$

$\mathrm{L}_{\mathrm{p}(\mathrm{Egli})}(\mathrm{dB})=\mathrm{P}_{\text {sys }}-20 \log \mathrm{h}_{(\mathrm{BST})}+85.9-10 \log \mathrm{h}_{(\mathrm{MS})}$, for $\mathrm{h}_{(\mathrm{MS})} \geq 10$

Where $\mathrm{P}_{\text {sys }}=20 \log \mathrm{f}_{\mathrm{c}}+40 \log \mathrm{d} \mathrm{h}_{(\mathrm{BST})}=$ height of the base station antenna $(\mathrm{m})$

$\mathrm{h}_{(\mathrm{MS})}=$ height of the mobile station antenna (m)

$\mathrm{d}=$ distance from base station antenna $(\mathrm{m})$

$\mathrm{f}_{\mathrm{c}}=$ transmission frequency $(\mathrm{MHz})$

\subsection{Okumura-Hata}

The model \%. on Okumura's measurement published in Tokyo in 1968 which was fitted in the mathematical model by Hata. This propagation path loss predicted model suits the urban area propagation [16-17]. Hata formulation is limited to the range of frequency between $150 \mathrm{MHz}-1500 \mathrm{MHz}$ and the base station antenna height is between $30 \mathrm{~m}$ to $200 \mathrm{~m}$. The term $\mathrm{an}\left(\mathrm{h}_{\mathrm{mb}}\right)$ is a correction factor for effective mobile antenna height which is a function of the size of the coverage area, the mobile antenna height ranging from $1 \mathrm{~m}-10 \mathrm{~m}$. The median path loss in urban areas is given by [14,18-19] as;

$\mathrm{L}_{\mathrm{P}}($ urban $) \mathrm{dB}=\mathrm{A}_{0}-13.82 \log _{10} \mathrm{~h}_{\mathrm{MS}}-\mathrm{a}\left(\mathrm{h}_{\mathrm{MS}}\right)+[44.9-$ $\left.6.55 \log _{10} \mathrm{~h}_{\mathrm{BST}}\right] \log _{10} d \quad(3)$

where $\quad \mathrm{A}_{0}=69.55+26.16 \log _{10} f$

$f$ is the carrier frequency (in MHz)

$\mathrm{h}_{\mathrm{BST}}=$ base station antenna height $(\mathrm{m})$

$\mathrm{h}_{\mathrm{MS}}=$ mobile antenna height (in metres)

$\mathrm{a}\left(\mathrm{h}_{\mathrm{MS}}\right)=$ correction factor for mobile antenna height

$\mathrm{d}=$ separation distance $($ in $\mathrm{km})$

Large city, the mobile antenna correction factor an $\left(\mathrm{h}_{\mathrm{MS}}\right)$ is given by

$$
\mathrm{a}\left(\mathrm{h}_{\mathrm{MS}}\right)=8.29\left[\log \left(1.54 \mathrm{~h}_{\mathrm{MS}}\right)\right]^{2}-1.1 \mathrm{~dB} \text { for } f \leq 300 \mathrm{Mhz}
$$

$\left(h_{M S}\right)=3.201\left[\log \left(11.75 h_{M S}\right)\right]^{2}-4.97 d B \quad$ for $f \geq$ $300 \mathrm{Mhz}$

Medium size city, the mobile antenna correction factor is

$$
a\left(h_{M S}\right)=1.11\left[\log \left(f_{c}\right)-0.7\right] h_{m b}-\left[1.56 \log \left(f_{c}\right)-0.8\right]
$$

To obtain the path loss in a suburban area the standard Hata formula in equation $(6)$ is modified $[4,20]$ as;

$$
\begin{aligned}
& L_{P(\text { OK-Hata })}(\text { suburban })(d B)=L_{P}(\text { urban }) d B- \\
& 2\left[\log \frac{f_{c}}{28}\right]^{2}-5.4
\end{aligned}
$$

\subsection{COST 231- Hata model}

The COST-231 is an improved version of the Hata model restricted to the following range of parameters: frequency of $1500-2000 \mathrm{MHz}$, base station antenna height of $30 \mathrm{~m}-$ $200 \mathrm{~m}$, mobile antenna height is between $1 \mathrm{~m}-10 \mathrm{~m}$, and separation distance $1 \mathrm{~km}-20 \mathrm{~km}$. The COST 231 is given by [21] as;

$$
\begin{gathered}
\mathrm{L}_{\mathrm{P}}(\mathrm{dB})=\mathrm{PL}_{0}-13.82 \log _{10} \mathrm{~h}_{\mathrm{BST}}-\mathrm{a}\left(\mathrm{h}_{\mathrm{MS}}\right)+ \\
{\left[44.9-6.55 \log _{10} \mathrm{~h}_{\mathrm{MS}}\right] \log _{10} d+\mathrm{C}_{\mathrm{K}}(8)}
\end{gathered}
$$

where

$$
\mathrm{PL}_{0}=46.3+33.9 \log _{10} f
$$

$\mathrm{C}_{\mathrm{K}}=$ Area correction factor

$\mathrm{L}_{\mathrm{P}}=$ path loss in $(\mathrm{dB})$

$f=$ the carrier frequency (in $\mathrm{MHz}$ )

$\mathrm{h}_{\mathrm{BST}}=$ Base station antenna height $(\mathrm{m})$

$\mathrm{h}_{\mathrm{MS}}=$ mobile antenna height ()

$\mathrm{a}\left(\mathrm{h}_{\mathrm{MS}}\right)=$ Correction factor for mobile station

$d=$ base station to mobile separation distance $(\mathrm{km})$

$\mathrm{C}_{\mathrm{K}}=0 d B$ for medium sized city and suburban areas and $3 d B$ for urban centers

For a large city, the mobile antenna correction factor is given by [22]

$$
\begin{aligned}
& \mathrm{a}\left(\mathrm{h}_{\mathrm{mb}}\right)=8.29\left[\log \left(1.54 \mathrm{~h}_{\mathrm{m}} \mathrm{b}\right)\right]^{2}-1.1 \mathrm{~dB} \text { for } \mathrm{f}_{\mathrm{c}} \leq 300 \mathrm{Mhz} \\
& a\left(h_{m b}\right)=3.2\left[\log \left(11.75 h_{m b}\right)\right]^{2}-4.97 \mathrm{~dB} \text { for } f_{c} \geq \\
& 300 \mathrm{Mhz}
\end{aligned}
$$

For a small or medium size city, the mobile antenna correction factor is

$$
a\left(h_{m b}\right)=1.1\left[\log \left(f_{c}\right)-0.7\right] h_{m}-\left[1.56 \log \left(f_{c}\right)-0.8\right]
$$

\section{REGRESSION ANALYSIS OF MEASURED DATA}

The regression analysis of measurement data is presented in Table 1. This is used to obtained statistical parameter for tuned values of the initial offset parameter and slope of the model curve. The measurement was taken at four different geographical location in Owerri namely- Egbu road (Location 1), Mbaise road (Location 2), Chukwuoma road (Location 3) and Awaka road (Location 4).

Table 1: Present Measured Path Loss (MPL) and Estimated Path Loss for Suburban

\begin{tabular}{|l|l|c|c|c|c|c|c|}
\hline $\begin{array}{l}\text { Dist } \\
(\mathrm{km})\end{array}$ & $\begin{array}{l}x_{i} \\
=10 \log \frac{d_{i}}{d_{0}}\end{array}$ & $\begin{array}{l}\text { MPL (Location } \\
\text { 1) }\end{array}$ & $\begin{array}{l}\text { MPL (Location } \\
2)\end{array}$ & $\begin{array}{l}\text { MPL (Location } \\
\text { 3) }\end{array}$ & $\begin{array}{l}\text { MPL (Location } \\
4)\end{array}$ & $\begin{array}{l}\text { Average PL } \\
\left(y_{i}\right)\end{array}$ & $y_{i}^{2}$ \\
\hline 100 & 0.000 & 95.1 & 108.5 & 97.7 & 106.1 & 101.9 & 10373.4 \\
\hline 200 & 3.010 & 118.2 & 106.6 & 125.8 & 117.2 & 116.9 & 13677.3 \\
\hline 300 & 4.770 & 148.2 & 151.53 & 108.8 & 147.2 & 138.9 & 19302.2 \\
\hline
\end{tabular}




\begin{tabular}{|l|l|c|c|c|c|c|c|}
\hline 400 & 6.021 & 131.03 & 134.5 & 132.7 & 130.1 & 132.1 & 17445.8 \\
\hline 500 & 6.990 & 164.5 & 139.9 & 134.1 & 135.5 & 143.5 & 20592.3 \\
\hline 600 & 7.782 & 144.5 & 114.9 & 154.03 & 125.5 & 134.7 & 18152.8 \\
\hline 700 & 8.451 & 121.3 & 131.7 & 122.9 & 120.3 & 124.1 & 15388.4 \\
\hline 800 & 9.031 & 95.6 & 131 & 125.2 & 126.6 & 119.6 & 14304.2 \\
\hline 900 & 9.542 & 139.7 & 143.1 & 144.3 & 138.7 & 141.5 & 20008.1 \\
\hline 1000 & 10.00 & 122.8 & 106.2 & 120.4 & 121.8 & 117.8 & 13876.8 \\
\hline 1100 & 10.41 & 140.9 & 144.3 & 156.5 & 139.9 & 145.4 & 21141.2 \\
\hline 1200 & 10.79 & 138.4 & 141.8 & 140 & 137.4 & 139.4 & 19432.4 \\
\hline 1300 & 11.14 & 106.4 & 126.8 & 144 & 137.33 & 128.6 & 16546.3 \\
\hline 1400 & 11.46 & 139.3 & 142.7 & 136.9 & 138.3 & 139.3 & 19404.5 \\
\hline 1500 & 11.76 & 135.1 & 123.5 & 136.7 & 134.1 & 132.4 & 17516.5 \\
\hline
\end{tabular}

\subsection{Model Validation}

It is important to evaluate the performance of propagation model considered to know which model can serve better for the area of application. The Root Mean Square Error (RMSE) and Mean Absolute Percentage Error (MAPE) [6] was calculated to estimate the better model for path loss prediction in Owerri. The best model for optimization was decided using (11) and (12). The result shows that COST 213-Hata model has $R M S E=9.75 d B$ and $M A P E=0.432 \%$ respectively.

$$
R M S E=\frac{1}{n} \sum_{t=1}^{n} \sqrt{\left(P_{m_{t}}-P_{R_{t}}\right)^{2}}
$$

Where: $P_{m_{t}}$ is the mean value of measured data, $P_{R_{t}}$ is the mean value of predicted path loss, $n$ is the number of data points.

\subsection{Optimization process}

The least square optimization method for COST 231- Hata model is presented in this section. In order to improve its performance as observed from the measured data, certain correction should be introduced to COST 231-Hata model. The most appropriate tool for such optimization may be the least square method [2]. The least square method (LSM) is a statistical method in which all environmental influences are considered. The COST 231- Hata model for suburban is given in equation (8) contains three basic elements:

$E_{0}=46.3+C_{K}$

$E_{\text {sys }}=33.9 \log _{10} f-13.82 \log _{10} h_{B S T}-a\left(h_{M S}\right)$

$\beta_{\text {sys }}=\left[44.9-6.55 \log _{10} h_{M S}\right] \log _{10} d$

Where $\mathrm{E}_{0}=$ initial offset parameter

$\mathrm{E}_{\text {sys }}=$ initial system design parameter

$\beta_{\text {sys }}=$ slope of the model curve

The total path loss from equation (8) is given by (15) as

$L_{P(\operatorname{Cos} T)}(d B)=E_{0}+E_{s y s}+\beta_{s y s}$

The condition of best fit of the theoretical curve with a given set of experimental data points using Statistical Least Square
Method (SLSM). The sum of deviation square is must be minimum [14].

$E_{P}(a, b, c, \ldots)=\sum_{i=1}^{N}\left[y_{i}-F_{R}\left(x_{i}, a, b, c, \ldots\right)\right]=\min$

Where $y_{i}=$ measured results at distance $x_{i}$

$F_{R}\left(x_{i}, a, b, c, \ldots\right)=$ predicted model results at distance $x_{i}$ based on optimization $E_{P}(a, b, c)=$ parameter of tuned model based on optimization

The required equations for $L_{P}$ to be minimum are;

$$
\frac{\partial E_{P}}{\partial a}=0, \frac{\partial E_{P}}{\partial b}=0, \frac{\partial E_{P}}{\partial c}=0
$$

The solution of (17) can the second edition based on (15) and the parameter of $E_{P}$ is expressed by equation (20) and (21); $\mathrm{L}_{\mathrm{P}(\operatorname{CosT})}(\mathrm{dB})=\mathrm{E}_{0}+\mathrm{E}_{\text {sys }}+\beta_{\text {sys }}$

$$
\begin{aligned}
& a=\mathrm{E}_{0}+\mathrm{E}_{\text {sys }} \\
& \mathrm{b}=\beta_{\text {sys }}
\end{aligned}
$$

This shows that the expression of COST 231-Hata model in (8) is given as;

$\mathrm{L}_{\mathrm{P}(\operatorname{Cos} \mathrm{T})}(\mathrm{dB})=\mathrm{a}+\mathrm{b} \log _{10} d$

Simplification of (22) through change of logarithm base; $\log _{10} d=x$, the above equation is presented as;

$\mathrm{L}_{\mathrm{P}(\operatorname{CosT})}(\mathrm{dB})=\mathrm{a}+\mathrm{b} . x$

Where $L_{P}$ is the model predicted path loss in decibels

From (22) both factors $\mathrm{a}$ and $\mathrm{b}$ are constants for a given system installation (base station and mobile station). Therefore, $a$ and $b$ are also constant for a set of measurement. The solution of (16) may be expressed by

$$
\begin{aligned}
& \sum_{i=1}^{N}\left[y_{i}-F_{R}\left(x_{i}, a, b, c\right)\right] \cdot \frac{\partial F_{R}}{\partial a}=\sum\left(y_{i}-a-b x_{i}\right) \cdot 1=0 \\
& \sum_{i=1}^{N}\left[y_{i}-F_{R}\left(x_{i}, a, b, c\right)\right] \cdot \frac{\partial F_{R}}{\partial b}=\sum\left(y_{i}-a-b x_{i}\right) \cdot x_{i}=0
\end{aligned}
$$

If equation (24) and (25) are reposition, the following expressions are generated

$$
\text { n. } a+b \sum x_{i}=\sum y_{i}
$$




$$
a \sum x_{i}+b \sum x_{i}^{2}=\sum\left(x_{i} \cdot y_{i}\right)
$$

By substituting the variables $a$ and $b$ into (24) and (27), this would give the statistically tuned estimates of parameters $a$ and $b$ as;

$$
\begin{aligned}
\tilde{a} & =\frac{\sum\left(x_{i}\right)^{2} \cdot \sum\left(y_{i}\right)-\sum\left(x_{i}\right) \cdot \sum\left(x_{i} \cdot y_{i}\right)}{n \cdot \sum\left(x_{i}\right)^{2}-\left(\sum x_{i}\right)^{2}} \\
\tilde{b} & =\frac{n \cdot \sum\left(x_{i} \cdot y_{i}\right)-\sum\left(x_{i}\right) \cdot \sum\left(y_{i}\right)}{n \cdot \sum\left(x_{i}\right)^{2}-\left(\sum x_{i}\right)^{2}}
\end{aligned}
$$

The tuned statistical parameter $\tilde{a}$ and $\tilde{b}$ access systems into original COST 213-Hata model for estimation comparison and tuned values of the initial offset parameter and slope of the model curve are predicted as given by [24] as;

$\tilde{E}_{0(\text { Tuned })}=\tilde{a}-E_{\text {sys }}$

$\tilde{\beta}_{\text {sys }}=\frac{\widetilde{\mathrm{b}}}{(44.9-6.55) \log _{10} h_{t x}}$

Where, $\tilde{a}, \tilde{b}, \tilde{E}_{0}, \tilde{\beta}$ are the mean values of a, b, $E_{0}, \beta$ respectively
The implementation of the least square algorithm is based on the work of [23]. The values of $\tilde{a}, \tilde{b}, \tilde{E}_{0(\text { Tuned })}$ and $\tilde{\beta}_{\text {sys }}$ were determined by substituting measured data into equation (28), (29), (30) and (31) and presented as followed; $\tilde{a}=115.81$, $\tilde{b}=1.8056 \tilde{E}_{0(\text { Tuned })}=41.424$, and $\tilde{\beta}_{\text {sys }}=0.05191$. The tuned value of $\tilde{E}_{0}$ was introduced into COST 231-Hata model and thus the optimized COST 231-Hata model is presented as equation (32).

$$
\begin{gathered}
L_{P}(d B)=41.42+33.9 \log _{10} f-13.82 \log _{10} h_{B S T}- \\
a\left(h_{M S}\right)+\left[44.9-6.55 \log _{10} h_{M S}\right] \log _{10} d+C_{K}
\end{gathered}
$$

Table 2 depicts the measured distance, average RSS, average values of the measured data obtained from four different locations in Owerri. The comparative analysis of the existing

\begin{tabular}{|c|c|c|c|c|c|c|}
\hline $\begin{array}{l}\text { Dist } \\
(\mathrm{m})\end{array}$ & $\begin{array}{l}\text { Average } \\
\text { RSS } \\
(\mathrm{dBm})\end{array}$ & $\begin{array}{l}\text { Average } \\
\text { Measured } \\
\text { PL (dB) }\end{array}$ & $\begin{array}{l}\text { Okumura- } \\
\text { Hata }(d B)\end{array}$ & $\begin{array}{l}\text { Cost231-Hata } \\
\text { (dB) }\end{array}$ & Egli (dB) & $\begin{array}{l}\text { Optimized } \\
\text { COST 231- } \\
\text { Hata (dB) }\end{array}$ \\
\hline 100 & -74.6 & 101.9 & 87.9 & 102.9 & 190.1 & 97.97 \\
\hline 200 & -85.2 & 116.9 & 98.4 & 113.3 & 202.1 & 108.45 \\
\hline 300 & -88.82 & 138.9 & 104.6 & 125.5 & 209.2 & 114.57 \\
\hline 400 & -91.91 & 132.1 & 108.9 & 134.8 & 214.2 & 118.92 \\
\hline 500 & -91.29 & 143.5 & 112.3 & 138.2 & 218.1 & 122.29 \\
\hline 600 & -83.46 & 134.7 & 115.0 & 140.9 & 221.2 & 125.04 \\
\hline 700 & -88.79 & 124.1 & 117.4 & 143.3 & 223.9 & 127.37 \\
\hline 800 & -84.82 & 119.6 & 119.4 & 145.3 & 226.2 & 129.39 \\
\hline 900 & -85.75 & 141.5 & 121.2 & 147.1 & 228.3 & 131.17 \\
\hline 1000 & -88.00 & 117.8 & 122.8 & 148.6 & 230.1 & 132.76 \\
\hline 1100 & -100.9 & 145.4 & 124.2 & 150.1 & 231.8 & 134.20 \\
\hline 1200 & -105.4 & 139.4 & 125.5 & 151.4 & 233.3 & 135.52 \\
\hline 1300 & -105.9 & 128.6 & 126.7 & 152.6 & 234.7 & 136.72 \\
\hline 1400 & -106.5 & 139.3 & 127.8 & 153.7 & 235.9 & 137.84 \\
\hline 1500 & -97.07 & 132.4 & 128.8 & 154.8 & 237.2 & 138.89 \\
\hline
\end{tabular}
models and optimized COST 231-Hata model was also presented after substituting both measured and relevant

\begin{tabular}{|c|c|c|c|c|c|}
\hline \multirow[t]{2}{*}{ Measurement Locations } & \multirow{2}{*}{$\begin{array}{l}\text { Performance } \\
\text { Metric }\end{array}$} & \multicolumn{3}{|c|}{ Existing Model } & \multirow{2}{*}{$\begin{array}{l}\text { Optimized COST } \\
231 \text { Model }\end{array}$} \\
\hline & & Ok-Hata (dB) & $\begin{array}{l}\text { COST 231- Hata } \\
\text { (dB) }\end{array}$ & Egli (dB) & \\
\hline \multirow[t]{2}{*}{ Error Analysis (Location 1) } & RMSE & 13.34 & 10.75 & 93.01 & 3.328 \\
\hline & MAPE & 0.687 & 0.554 & 4.792 & 0.171 \\
\hline \multirow[t]{2}{*}{ Error Analysis (Location 1) } & RMSE & 13.74 & 10.35 & 92.61 & 3.730 \\
\hline & MAPE & 0.706 & 0.532 & 4.757 & 0.192 \\
\hline
\end{tabular}
network parameters of the models.

Table 2. Shows results of measured path loss value and prediction from existing model

Table 3: Performance analysis of the models 


\begin{tabular}{|l|l|l|l|l|l|}
\multirow{2}{*}{ Error Analysis (Location 1) } & RMSE & 15.94 & 8.150 & 90.41 & 5.930 \\
\cline { 2 - 6 } & MAPE & 0.805 & 0.412 & 4.566 & 0.299 \\
\hline \multirow{2}{*}{ Error Analysis (Location 4) } & RMSE & 14.34 & 9.750 & 92.01 & 4.330 \\
\cline { 2 - 6 } & MAPE & 0.733 & 0.499 & 4.704 & 0.221 \\
\hline $\begin{array}{l}\text { Average Error Analysis } \\
\text { (Location 1-4) }\end{array}$ & RMSE & 14.34 & 9.750 & 92.01 & 4.330 \\
\cline { 2 - 6 } & MAPE & 0.733 & 0.432 & 4.705 & 0.221 \\
\hline
\end{tabular}

\section{RESULTS AND DISCUSSION}

The propagation loss has been estimated using OkumuraHata, COST 231-Hata, and Egli models. The RMSE and MAPE were calculated to verify the accuracy and suitability of the best fit model for optimization. COST 231-Hata model was selected and optimized using Least Square Method (LSM). At $100 \mathrm{~m}$ away from the base station, the path loss values obtained are, $87.9 \mathrm{~dB}, 102.9 \mathrm{~dB}, 190.1 \mathrm{~dB}, 97.97 \mathrm{~dB}$ for Okumural - Hata, COST 231-Hata, Egli, OptimizedCOST 231 respectively. Also, at a distance of $1500 \mathrm{~m}$, the path losses values obtained are $128.8 \mathrm{~dB}, 154.8 \mathrm{~dB}, 237.2 \mathrm{~dB}$ and $138.89 \mathrm{~dB}$. Figure 1 presented the plot of optimized COST 231-Hata with measured for location 1, the result showed that RMSE was $3.328 d B$ and MAPE was $0.171 \%$. Figure 2 shows the comparative plot of measured, existing and optimized COST 231-Hata models for location 2 where RMSE gave $3.73 d B$ and MAPE gave $0.192 \%$. Also, figure 3 showed the Plot of measured path loss, existing model and optimized model for location 3 with RMSE of $5.93 \mathrm{~dB}$ and MAPE $0.299 \%$. Figure 4 presented the plot of the result at location 4, RMSE and MAPE values are $4.33 \mathrm{~dB}$ and $0.221 \%$ respectively. The results as depicted in figure 14 shows that optimized model gave a better performance compared to COST 231-Hata model, thus the optimized model is successfully developed. The average results show that optimized model has RMSE of $4.33 d B$ and MAPE of $0.221 \%$ respectively. The optimized model gave good results for distance above $600 \mathrm{~m}$ which is very important for coverage calculation, interference consideration, and good network handoff. Therefore, optimized COST 231-Hata model can be used for path loss estimation in a suburban area.

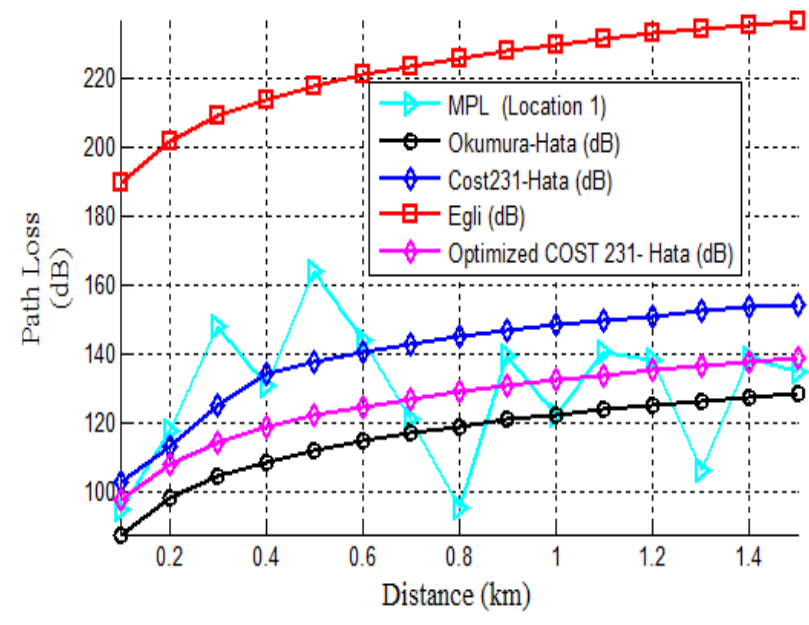

Figure 1: Plot of optimized COST 231-Hata with measured for location 1

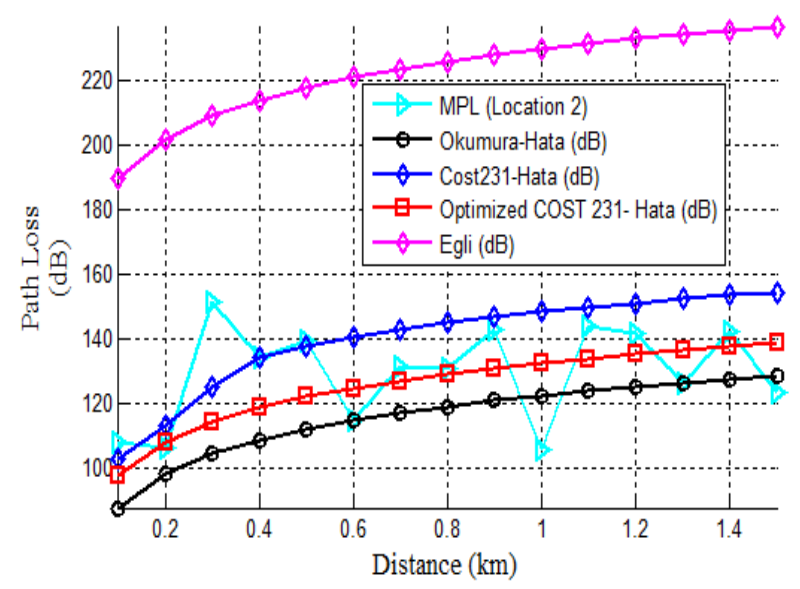

Figure 2; Comparative plot of measured, existing and optimized COST 231-Hatamodels for location 2

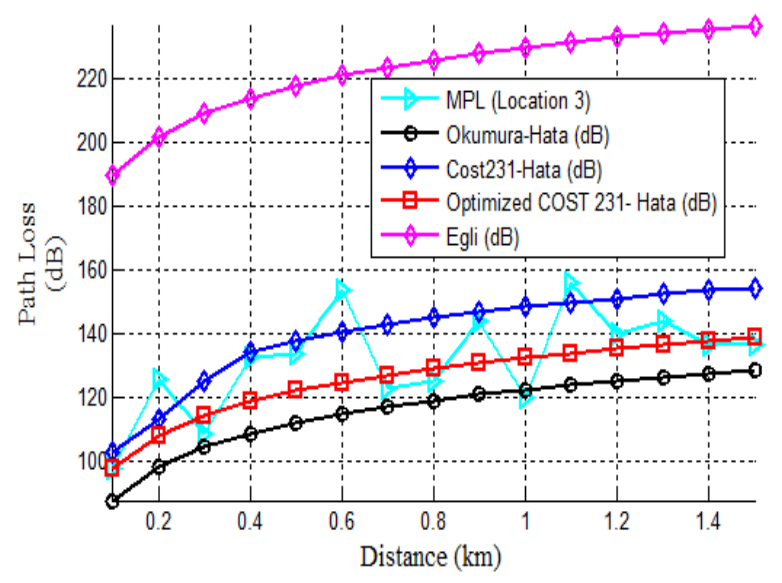

Figure 3: Plot of measured path loss, existing model and optimized model for location 3

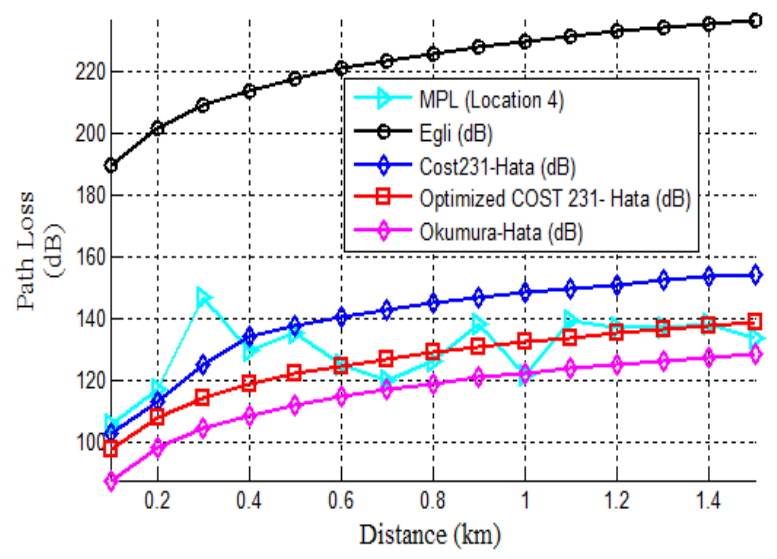

Figure 4: Plots of measured, existing model and optimized COST 231-Hata for location 4 


\section{CONCLUSION}

The RSS of mobile radio communication at $2100 \mathrm{MHz}$ was measured in Egbu-Abba Road, Owerri suburban area. The measured path loss was compared with calculated path loss from the existing known models. The RMSE and MAPE were evaluated, COST 231-Hata gave the closest prediction. The results obtained from COST 231-Hata model still recorded high deviation from the actual path loss. This model was optimized using LSM to obtain better prediction results. The optimized COST 231-Hata model gave the best result for the prediction of signal strength in Owerri, suburban area. This model is useful for telecommunication provider to improve their service for better mobile user satisfaction with low calls drop and better handoff process.

\section{REFERENCES}

[1] Ogbulezie, J.C, Onuu, M.U, Bassey, D.E and EtienamUmoh, S (2013), "Site specific measurements and propagation models for GSM in three cities in Northern Nigeria". American Journal of Scientific and Industrial Research, vol.4, no. 2. pp 238-245.

[2] Aied. K. M and Ahmed, A. J (2012), "Performance Evaluation of Path Loss in Mobile Channel for Karada District in Baghdad City", Engineering and Technology journal vol. 30, no. 17, pp. 3023-3037.

[3] Adeyemo. Z. K, Ogunremi. O. K. Akande. A. O (2016), "Genetic Algorithm Based Path loss Optimization for Long Term Evolution in Lagos, Nigeria", International Journal of Applied Science and Technology vol. 6, No. 2, pp.79-88.

[4] Rappaport, T.S. (2002), "Wireless Communications Principles and Practice", second edition, Prentice Hall. New Jersey.

[5] Okumura, Y., Ohmori, E., Kawano, T., and Fukuda, K. (1968), "Field strength and its variability in VHF and UHF land mobile radio service. Review of Electrical and Communication Laboratory, vol. 16, no 9-10, pp. 825-873.

[6] Erceg V. and Greenstein L. J (1999), “An empirically based path loss model for wireless channels in suburban environments", IEEE Journal on Selected Areas in Communications, vol. 17, no. 7 pp. 1205-1211.

[7] Abhayawardhana V.S, Wassell I.J, Crosby D, Sellars M.P and Brown M.G (2005), "Comparison of empirical propagation path loss models for fixed wireless access systems" IEEE $61^{\text {st }}$ Vehicular Technology Conference, vol. 1, pp. 73-77.

[8] Crane R. K. (1980), "Prediction of attenuation by rain," IEEE Transactions on Communications, vol. 28, no 2, pp. 1727-1732.

[9] Erceg, V. and Hari, K. V. S (2001), "Channel Models for fixed Wireless Applications, Technical Report on IEEE 802.16 Broadband Wireless Access Working Group, pp.1-36, Available on http://ieee.org/16 and Retrieved on June 20, 2016.

[10] Egli, J. J (1957), "Radio Propagation above 40 MHz over Irregular Terrain". Proc. IRE (IEEE), vol.45, no.10, pp $1381-1391$
[11] Sridhar B and Mohammed Z. A. K (2015), "A Novel LMMSE Based Optimized Perez-Vega Zamanillo Propagation Path Loss Model in UHF / VHF Bands for India”, Progress In Electromagnetics Research B, vol. 63, pp. 17-33.

[12] Sridhar, B. and Khan, M. Z. A (2014), "RMSE comparison of path loss models for UHF/VHF bands in India", IEEE Region 10 Symposium, pp. 330-335, Kuala Lumpur, Malaysia.

[13] Mardeni R and Kwan K. F (2010), “Optimization of Hata Propagation Prediction Model in Suburban Area in Malaysia", Progress In Electromagnetics Research C, vol. 13, pp. 91-106.

[14] Obot A. Simeon O. and Afolayan .J (2011), "Comparative Analysis of Path Loss Prediction Models for Urban Macrocellular Environments", Nigerian Journal of Technology, vol. 30, no. 3, pp. 50-59.

[15] Sanjay Sharma (2013), "Mobile and Wireless Communications" fourth edition, Kataria \& Sons publishers, New Delhi.

[16] Hata, M (1980), "Empirical Formula for Propagation Loss in Land Mobile Radio Services", IEEE Transactions on Vehicular Technology, vol.29, no. 3, pp. 318-325.

[17] Nadir, Z. E, N. and Touati, F (2008), "Path loss Determination Using Okumura - Hata Model and Spline Interpolation for Missing Data for Oman", Proceedings of the World Congress on Engineering, vol. 1, pp.20-26. London, United Kingdom.

[18] Pathania, P., P. K, and Shashi, R. B (2014), “A modified formulation of path loss models for broadcasting applications," International Journal of Recent Technology and Engineering (IJRTE), vol. 3, no. 3, pp. 44-54.

[19] Alexander, M. R. (2009), "Understanding and Predicting Urban Propagation Losses", M.Sc. Thesis, Naval Postgraduate School, Australia.

[20] COST 231 (1991), European Cooperative in the Field of Science and Technical Research Euro-Cost 231, "Urban transmission loss models for mobile radio in the 900 MHz and $1800 \mathrm{MHz}$ bands", (Revision 2), Netherlands.

[21] Stuber, G. L (2001), "Principles of Mobile Communication", second edition, Kluwer Academic Publishers, Boston.

[22] Jadhav A.N and Kale-Sachin S (2014), "Suburban Area Path loss Propagation Prediction and Optimization using Hata Model at 2375 MHz", International Journal of Advanced Research in Computer and Communication Engineering", Vol 3, no. 1, pp. 5004 5008 .

[23] Bhuvaneshwari, R. Hemalatha, and T. Satyasavithri (2013), "Statistical Tuning of the Best suited Prediction Model for Measurements made in Hyderabad City of Southern India" Proceedings of the world congress on engineering and computer science, vol II WCECS, San Francisco, USA. 